\title{
The Simultaneous Effects of Inflectional Paradigms and Classes on Lexical Recognition: Evidence from Serbian
}

\author{
Petar MILIN \& Dušica FILIPOVIĆ ĐURĐEVIĆ \\ University of Novi Sad \& University of Belgrade, Serbia
}

Fermín MOSCOSO DEL PRADO MARTÍN

Aix-Marseille Université \& C.N.R.S., Marseilles, France

Draft of August 31, 2008

\begin{abstract}
In this study, we investigate the relevance of inflectional paradigms and inflectional classes for lexical processing. We provide an informationtheoretical measure of the divergence in the frequency distributions of two of the paradigms to which a word simultaneously belongs: the paradigm of the stem, and the more general paradigm of the nominal class in which the stem is embedded. We show that after controlling for other variables, this measure is positively correlated with response latencies and error counts in a visual lexical decision experiment in Serbian. We interpret these results as a trace of the simultaneous influence on lexical processing of both, the stem and the inflectional paradigms.

Keywords: inflectional paradigm, inflectional class, frequency effect, information theory, visual lexical decision, Serbian
\end{abstract}

\section{Introduction}

An inflectional paradigm (IP) can be defined as the set of inflected variants that can be formed for a word by regular or predictable morphological transformations. IPs have long held a prominent role in the study of language as one of the fundamental building blocks of the lexicon (cf., Anderson, 1992; Aronoff, 1994; Blevins, 2003; De Saussure, 1966/1916; Kuryłowicz, 1964; Wunderlich \& Fabri, 1995; Zwicky, 1985, but for linguistic views that reject the relevance of IPs see also: Halle \& Marantz, 1993; Lieber, 1992). A classical example of an IP is presented in Table 1, which shows the inflected variants for the Latin

This work was partially supported by the Ministry of Science and Environmental Protection of the Republic of Serbia (grant number: 149039D). The third author was funded by the European Commission through a Marie Curie Individual Fellowship (MC-EIF-010318).

We wish to thank R. Harald Baayen, James P. Blevins and Aleksandar Kostić for their generous advice. Also, we thank Cristina Burani, Joseph Stemberger and one anonymous reviewer for their constructive criticism of an earlier version of this paper. Correspondence can be addressed to pmilin@ff.ns.ac.yu 
Table 1: The inflectional paradigm for the Latin feminine noun "puella" (girl).

\begin{tabular}{lll}
\hline CASE & SINGULAR & PLURAL \\
\hline nominative & puell-a & puell-ae \\
genitive & puell-ae & puell-arum \\
dative & puell-ae & puell-is \\
accusative & puell-am & puell-as \\
vocative & puell $-\mathbf{a}$ & puell-ae \\
ablative & puell-a & puell-is \\
\hline
\end{tabular}

noun "puella" (girl). Similarly, an inflectional class (IC) is a set of words that form their IPs in the same way. For instance, the first declension of Latin nouns - to which "puella" belongs - would be a typical example of an IC. Note that, any other word belonging to this class (mostly composed of feminine nouns) would form its inflected variants using the same exponents or inflectional endings at the level of a given IC (cf., Matthews, 1991). Thus the accusative singular of "rosa" (rose) would be "rosam" and the accusative singular of "terra" (land/earth/ground) would be "terram". ICs - also referred to as declension or conjugation classes - have been recognized since antiquity as very useful tools for the description and teaching of languages, and were adopted as important building blocks of the lexicon by early Latin and Greek grammarians (see Matthews, 1991).

The role of IPs

Psycholinguistic researchers interested in morphology have paid greater attention to the role of IPs than ICs. On the one hand, a large body of evidence has documented that the probabilistic properties of morphological constituents influence lexical processing (see Hay \& Baayen, 2005, for a detailed review). Taft (1979) and Colé, Beauvillain, and Segui (1989) report that the summed frequency of all the inflected variants of a word - its stem frequency - co-determines the response latencies to suffixed words in visual lexical decision experiments. On the other hand, some authors have directly investigated the role of IPs in the processing of inflectionally rich languages (for German: Clahsen, 1999; Clahsen, Hadler, Eisenbeiss, \& Sonnenstuhl-Henning, 2001; Janssen \& Penke, 2002; for Finnish: Bertram, Laine, Baayen, Schreuder, \& Hyönä, 2000; Hyönä, Laine, \& Niemi, 1995; for Italian: Burani, Salmaso, \& Caramazza, 1984; Caramazza, Laudanna, \& Romani, 1988; for Serbian: A. Kostić, 1991, 1995; Lukatela, Gligorijević, Kostić, \& Turvey, 1980).

The Italian studies (Colombo \& Burani, 2002; Traficante \& Burani, 2003) suggest that the number of inflected variants in which a word can appear (i.e., its inflectional family size) is positively correlated with the lexical decision latencies to that word. For instance, Italian adjectives have fewer inflected variants than verbs, and the study by Taficante and Burani reports that adjectives are recognized faster than verbs. Note that these results by themselves do not clarify whether the latency differences are due to the words having a different number of inflected variants, or simply to them being from different grammatical categories. The inflectional family size interpretation would predict that, even within the same grammatical category, words having more inflected forms should be recognized faster. 
However, due to experimental design Traficante and Burani were not able to look at the correlation between inflectional family size and lexical decision latencies, which then allows a more parsimonious explanation that the effect they observed was due to differences in grammatical category.

In related strand, Baayen, Feldman, and Schreuder (2006) and Moscoso del Prado Martín, Kostić, and Baayen (2004) demonstrated that both the number of inflected variants of a word, and their relative frequency distribution influence lexical decision latencies: Words with a larger number of inflected variants are recognized faster than words with fewer inflected variants, and the more balanced the frequency distribution of these variants, the faster people recognize words. Crucially, this holds also between words within the same grammatical category (i.e., nouns and verbs in English and Dutch). The authors took these results as evidence that the properties of IPs do indeed influence response latencies in visual lexical decision.

The role of $I C s$

All of the findings reported above refer to the properties of particular stems or lemmas, but not to the more general ICs. In this respect, Kostić and his collaborators have repeatedly reported effects of the statistical distribution of forms within an IC, irrespective of the particular stem being processed (A. Kostić, 1991, 1995; A. Kostić, Marković, \& Baucal, 2003). Kostić and colleagues defined the amount of information of an exponent within a given IC as the log-ratio of the average probability per syntactic function/meaning, weighted by the sum of the averaged probabilities of all inflectional exponents within a given IC. Then, in a series of visual lexical decision experiments, they reported high positive correlation between the mean latencies and the weighted information scores for exponents of Serbian ICs.

Similarly, Baayen and Moscoso del Prado Martín (2005) report that the properties of different regular and irregular verbal ICs in Germanic languages can influence the results of different types of behavioral and neuroimaging experiments. Irregular verbal ICs in English, German and Dutch are characterized by greater semantic density, which facilitates lexical processing (see also Tabak, Schreuder, \& Baayen, 2005). However, all evidences for ICs is weakened by the fact that, by averaging across all words within the class, it is not clear whether the effects observed are due to the general ICs themselves or to the effects of the words' IPs, where the latter would be fully in line with the effects reported by Baayen et al. (2006) and Moscoso del Prado Martín et al. (2004).

The interplay of IPs and ICs in lexical processing

In a study on the processing of singular and plural forms in Dutch, Baayen, Dijkstra, and Schreuder (1997) examined lexical decision latencies for two types of nouns: Nouns for which the singular form is more frequent than the plural form, and nouns in which the plural form is the more frequent one. They reported that response latencies for singulardominant nouns are influenced by the stem frequency (or the summed frequency of the singular and plural forms), whereas the processing of plural-dominant nouns seems to be additionally influenced by their surface frequency. These results were replicated in English and French by New, Brysbaert, Segui, and Rastle (2004) and in Italian by Baayen, Burani, and Schreuder (1997). These studies investigated the different effects of whole form and 
stem frequency for singular- and plural-dominant words. However, they did not provide much discussion on the possible relevance of the degree of singular/plural dominance for a given word stimuli, nor the relevance of the match between that degree and the degree of singular/plural dominance in the lexicon as a whole. For example, we could think of a noun which has $p_{S g}=0.4$ and $p_{P l}=0.6$, and another one with $p_{S g}=0.1$ and $p_{P l}=0.9$, where in the whole lexicon singular/plural ratio is $p_{S g}=0.38$ and $p_{P l}=0.62$. Then, we could ask ourselves whether both the singular/plural ratio at the level of individual stems, and the distance of that ratio from the ratio in the lexicon, influence lexical processing over and above other known factors. Indeed a factor that could possibly have influenced the results of Baayen and colleagues and New and colleagues is the degree of mismatch between the frequency distribution of forms for a particular stem, and the frequency distribution of forms in the broader IC. Investigating this mismatch could provide evidence for the simultaneous relevance of IPs and ICs on lexical recognition.

In summary, various authors have considered a possible role of IPs or ICs for the processing of words in the human mind. On the one hand, some of them have presented evidence for the IP of a particular word playing a role (e.g., Baayen et al., 2006; Clahsen et al., 2001; Janssen \& Penke, 2002; Moscoso del Prado Martín et al., 2004; Colombo \& Burani, 2002), but have neglected the role of the more general IC. On the other hand, another group of studies (A. Kostić, 1991, 1995; A. Kostić \& Katz, 1987; A. Kostić et al., 2003; Baayen \& Moscoso del Prado Martín, 2005) have considered the influence of the general IC but have ignored the influence of the IP of individual words and/or the possible differences that may arise when processing different parts of speech (cf., Bak, G., Xuereb, Boniface, \& Hodges, 2001; Bird, Howard, \& Franklin, 2001; Damasio \& Tranel, 1993; Tyler, Russel, Fadili, \& Moss, 2001). In addition, the studies by Baayen, Dijkstra, and Schreuder (1997), Baayen, Burani, and Schreuder (1997) and New et al. (2004) hint at the possibility of a simultaneous influence of both the word's local IP and its more general IC. It is clear that a demonstration of the role of both IPs and ICs needs to explicitly consider the simultaneous influence of both levels of morphological relationships within a single grammatical category.

\section{The current study}

In this study, we investigate the role of IPs and ICs in the nominal system of Serbian. Serbian is a language belonging to the Southern subgroup of the Slavic language family. Currently, Serbian is considered a bi-alphabetic language: It can be written using both the Serbian Cyrillic alphabet or an adaptation of the Latin alphabet (which is common to other languages of the former Yugoslavia). ${ }^{1}$ Partly thanks to the relative shallowness of the sound-to-spelling mappings, conversion between both alphabets is mostly a matter of direct context-free letter substitution using a one-to-one letter mapping. ${ }^{2}$

As is the case in most other Slavic languages, when compared to modern Germanic or Romance languages, Serbian exhibits a relatively complex nominal inflection system. In

\footnotetext{
${ }^{1}$ Serbian children are trained in the use of both the Cyrillic and Latin alphabets from an early age, with an offset of one year between the beginning of Cyrillic and Latin script education. Both alphabets are widely used in handwriting, books, newspapers, product labeling, or restaurant menus. In fact, if anything, the Latin script is dominant in every day usage in Serbia.

${ }^{2}$ With the exception of the Latin digraphs 'lj', 'nj', and 'dž', each of which is mapped to a single Serbian Cyrillic character.
} 
Table 2: Declension tables for Serbian regular masculine and feminine nouns, showing the inflectional exponents that are added to the stems to form different inflected forms. The upper part of the table shows the masculine inflections exemplified on the noun "prostor" (space). The lower part shows the feminine inflections on the noun "planina" (mountain). These are the two Serbian ICs used in our study.

\begin{tabular}{|c|c|c|}
\hline \multicolumn{3}{|c|}{ MASCULINE NOUNS } \\
\hline Case & Singular & Plural \\
\hline nominative & prostor- $\varnothing$ & prostor $\mathbf{- i}$ \\
\hline genitive & prostor-a & prostor-a \\
\hline dative & prostor-u & prostor-ima \\
\hline accusative & prostor- $\varnothing$ & prostor-e \\
\hline vocative & prostor-e & prostor-i \\
\hline instrumental & prostor-om & prostor-ima \\
\hline locative & prostor-u & prostor-ima \\
\hline \multicolumn{3}{|c|}{ FEMININE NOUNS } \\
\hline Case & Singular & Plural \\
\hline nominative & planin-a & planin-e \\
\hline genitive & planin-e & planin-a \\
\hline dative & planin-i & planin-ama \\
\hline accusative & planin-u & planin-e \\
\hline vocative & planin-o & planin-e \\
\hline instrumental & planin-om & planin-ama \\
\hline locative & planin-i & planin-ama \\
\hline
\end{tabular}

a manner similar to the Latin example described above, each Serbian noun is marked for case and number (singular or plural). Serbian nouns can appear in six different inflectional cases that determine the syntactic function of the word within the sentence: nominative, genitive, dative, accusative, instrumental and locative. Additionally, Serbian nouns can also engage in vocative function, but the status of the vocative as a full-fledged case in modern Serbian is under question (cf., Đ. Kostić, 1965).

Interestingly, regular Serbian nouns can form their inflected variants following one of four ICs (which are greatly determined by the gender of the word). ${ }^{3}$ For instance, most Serbian feminine nouns belong to an IC where the nominative singular ends in - $a$ (e.g., "žena" - woman [nom. sg.], "domaćica" - housewife [nom. sg.], etc.), and form their case-number marked forms using the same terminations (see Table 2).

In what follows, we address the issue of the simultaneous relevance of IPs and ICs for lexical recognition. We begin by providing a characterization of the difference between the frequency distributions of a stem's IP and its broader IC. For this we provide a measure motivated by information theory - that can be used for any type of morphological paradigm, since the simple dominance measure, such as singular-dominant vs plural-dominant categories, used by Baayen, Dijkstra, and Schreuder (1997) and subsequent studies is only useful

\footnotetext{
${ }^{3}$ Some additional subclasses can be distinguished within these. In this study, we will consider only the dominant subclass within each of the main classes.
} 
for the very simple paradigms having only two forms. Our measure enables us to consider the simultaneous influence of IPs and ICs in complex systems such as that of Serbian. We continue by using our measure to investigate the influence of paradigms and classes on lexical recognition: Does the level of discrepancy between a word's IP and the nominal IC to which it belongs affect lexical decision latencies and error counts? For this we present the results of a lexical decision experiment in Serbian, where we have varied this discrepancy. Finally, we outline the implications of our results for theories on the organization of the mental lexicon.

\section{Quantifying the relationship between IP and IC distributions}

We hypothesize that lexical processing is simultaneously influenced by at least two word frequency distributions: the local distribution of the word's IP, and the global distribution of the more general IC to which the word belongs. The situation in languages with relatively complex inflectional systems is illustrated in Figure 1. The three plots illustrate frequency distributions of the IPs of three Serbian regular feminine nouns, along with the global (i.e., average) frequency distribution of the IC to which these three nouns belong. The deviation between the local and global distributions grows from the left to right: on the leftmost plot, the two distributions are very similar; on the middle plot, the deviation between both distributions is moderate; the rightmost plot shows two very divergent distributions. If our hypothesis is correct, response latencies to these three nouns (i.e., stems or lemmas) should correlate with the magnitude of the deviation between the two frequency distributions, as presented in Figure 1.

We quantified the IP distributions in the same way as Moscoso del Prado Martín et al. (2004). They characterized distributional properties of IPs using inflectional entropy, that is, the informational entropy (Shannon, 1948) calculated over the relative frequencies of the inflected variants of a given word. If word $w$ has $n$ inflected variants each occurring with a frequency $f\left(w_{i}\right)$, the inflectional entropy of the word $w$ is defined as:

$$
\begin{aligned}
H I(w) & =-\sum_{i=1}^{n} p\left(w_{i}\right) \log _{2} p\left(w_{i}\right) \\
& =-\sum_{i=1}^{n} \frac{f\left(w_{i}\right)}{f(w)} \log _{2} \frac{f\left(w_{i}\right)}{f(w)}
\end{aligned}
$$

where $f(w)$ is the cumulative stem frequency of $w\left(f(w)=\sum_{i=1}^{n} f\left(w_{i}\right)\right)$. This measure correlates negatively with lexical decision response latencies in English and Dutch (Baayen \& Moscoso del Prado Martín, 2005; Moscoso del Prado Martín et al., 2004; Baayen et al., 2006).

We could also calculate the entropy of the distribution of inflectional exponents within the global IC in a similar way as for the local IP. However, this value is a constant for any given IC. Thus, our hypothesis is that it is the difference (i.e., deviation) between the IP and IC that has an impact on word recognition. Information Theory (for an introduction to the information-theoretical concepts employed here see Chapters $1 \& 2$ of Cover \& Thomas, 1991) offers us a straightforward measure of the degree of divergence between two probability distributions $p$ and $q$ - the relative entropy (or Kullback-Leibler divergence; $D(p \| q)$ ) between them: 

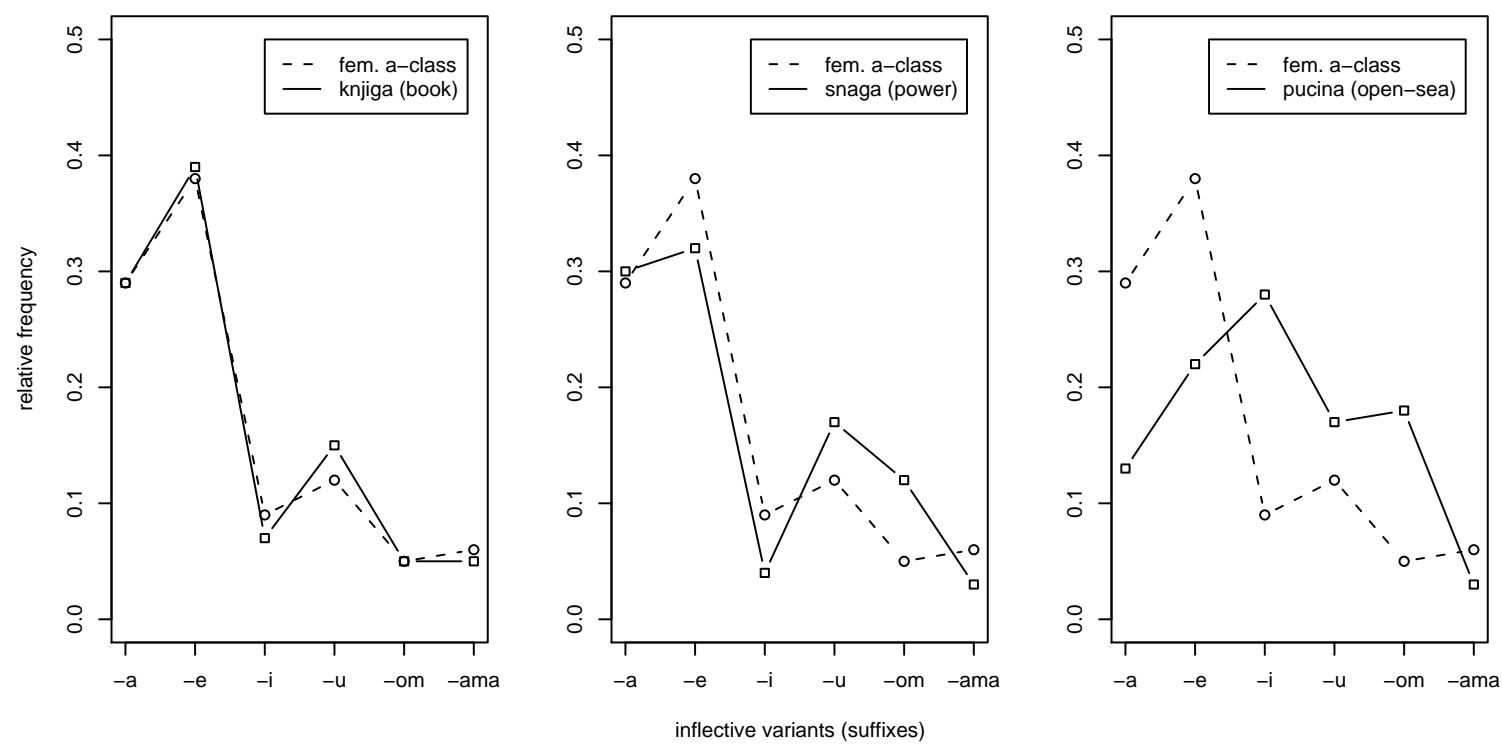

Figure 1. Examples of the relationship between the frequency distributions of the IPs of three Serbian feminine nouns and the frequency distribution of the IC to which they belong. The horizontal axis represents regular inflected variants for feminine nouns belonging to the 3rd IC, while vertical axis represents the corresponding relative frequencies. The dashed lines represent the global frequency distribution of the Serbian regular feminine IC, and the solid lines represent the frequency distribution for each particular stem ("knjiga" - book on the left, "snaga" - power in the middle, and "pučina" - open-sea on the right).

$$
\begin{aligned}
D(p \| q) & =\sum_{i \in \mathcal{P}} p(i) \log _{2} \frac{p(i)}{q(i)} \\
& =\sum_{i \in \mathcal{P}} f\left(w_{i}\right) / f(w) \log _{2} \frac{f\left(w_{i}\right) / f(w)}{f\left(e_{i}\right) / f(e)}
\end{aligned}
$$

where the $i$ are the possible inflected variants contained within IP $\mathcal{P}$, and $p(i), q(i)$ are the probabilities of the inflected form $i$ according to the distributions $p$ and $q$. Relative entropy is calculated by direct application of $(2) . f(w)$ is the cumulative stem frequency of word $w, f\left(e_{i}\right)$ is the summed frequency of all words within the same IC of $w$ in the same inflected variant (i.e., the inflectional exponent frequency), and $f(e)$ is the cumulative frequency of all inflected words within the IC (i.e., the cumulative inflectional exponent frequency, $\left.f(e)=\sum_{i=1}^{n} f\left(e_{i}\right)\right)$.

Consider the noun example "planina" (mountain) in Table 2. We can calculate its inflectional entropy and its relative entropy by the following steps. First, we collapse the different cases into inflected variants (i. e., identical orthographic forms). For "planina", the 14 entries in the declension table (Table 2, lower part) reduce to the six inflected variants shown in Table 3 . In the second column of the Table 3 surface frequency counts $\left(f\left(w_{i}\right)\right)$ for each inflected form of the word are given. Then, each entry in the second column is divided 
Table 3: The inflected variants of the feminine noun "planina" (mountain). Columns present frequencies and relative frequencies of the respective inflectional paradigm and the class to which it belongs.

\begin{tabular}{lllll}
\hline $\begin{array}{l}\text { Inflected } \\
\text { variant }\end{array}$ & $\begin{array}{l}\text { Inflected variant } \\
\text { (surface) } \\
\text { frequency } \\
f\left(w_{i}\right)\end{array}$ & $\begin{array}{l}\text { Inflected variant } \\
\text { (surface) } \\
\text { relative frequency } \\
p\left(w_{i}\right)=f\left(w_{i}\right) / f(w)\end{array}$ & $\begin{array}{l}\text { Inflectional } \\
\text { exponent } \\
\text { frequency } \\
f\left(e_{i}\right)\end{array}$ & $\begin{array}{l}\text { Inflectional } \\
\text { exponent } \\
\text { relative frequency } \\
p\left(e_{i}\right)=f\left(e_{i}\right) / f(e)\end{array}$ \\
\hline planin- $a$ & 169 & 0.31 & 18715 & 0.26 \\
planin- $u$ & 48 & 0.09 & 9918 & 0.14 \\
planin- $e$ & 191 & 0.35 & 27803 & 0.39 \\
planin- $i$ & 88 & 0.16 & 7072 & 0.10 \\
planin- om & 30 & 0.05 & 4265 & 0.06 \\
planin- $a m a$ & 26 & 0.05 & 4409 & 0.06 \\
\hline
\end{tabular}

by the total for that column $(f(w)=552)$, and the results are shown in the third column $\left(p\left(w_{i}\right)=f\left(w_{i}\right) / f(w)\right)$. The fourth column represents the inflectional exponent frequency $\left(f\left(e_{i}\right)\right)$, which is the summed frequency for each inflectional ending of all words belonging to the same IC. Finally, the fifth column is obtained by dividing each entry in the fourth column by the total for the forth column $\left(f(e)=72182\right.$, and $\left.p\left(e_{i}\right)=f\left(e_{i}\right) / f(e)\right)$.

We can now apply (1) and (2) to calculate inflectional entropy $(H I)$ and relative entropy $(D(p \| q))$ for the word in the Table 3 :

$$
\begin{aligned}
H I(\text { planina }) & =-\sum_{i=1}^{n} p\left(w_{i}\right) \log _{2} p\left(w_{i}\right) \\
& =-\sum_{i=1}^{n} \frac{f\left(w_{i}\right)}{f(w)} \log _{2} \frac{f\left(w_{i}\right)}{f(w)} \\
& =-\left[\left((169 / 552) \times \log _{2}(169 / 552)\right)+\ldots+\left((26 / 552) \times \log _{2}(26 / 552)\right)\right] \\
& =-\left[\left(0.31 \times \log _{2} 0.31\right)+\ldots+\left(0.05 \times \log _{2} 0.05\right)\right] \\
& =-[-0.52-0.31-0.53-0.42-0.22-0.22] \\
& =2.22 \\
D(\text { planina } \| a-\text { class }) & =\sum_{i \in \mathcal{P}} p(i) \log _{2} \frac{p(i)}{q(i)} \\
& =\sum_{i \in \mathcal{P}} f\left(w_{i}\right) / f(w) \log _{2} \frac{f\left(w_{i}\right) / f(w)}{f\left(e_{i}\right) / f(e)} \\
& =\left[\left((169 / 552) \times \log _{2} \frac{(169 / 552)}{(18715 / 72182)}\right)+\ldots+\left((26 / 552) \times \log _{2} \frac{(26 / 552)}{(4409 / 72182)}\right)\right] \\
& =\left(0.31 \times \log _{2} \frac{0.31}{0.26}\right)+\ldots+\left(0.05 \times \log _{2} \frac{0.05}{0.06}\right) \\
& =0.08-0.06-0.05+0.11-0.01-0.01 \\
& =0.05
\end{aligned}
$$


Similarly, returning to the examples on Figure 1, the inflectional entropies would be (from left to right) $2.17 \mathrm{bits}, 2.22 \mathrm{bits}$, and $2.39 \mathrm{bits}$, while the relative entropies between the local and global distributions would be (from left to right) 0.01 bits, 0.11 bits (which is actually the median deviation in our dataset), and 0.49 bits. Note that, as desired, the magnitude of the relative entropy increases from left to right: the more different the two distributions are, the greater the relative entropy between them. Restating our hypothesis above, the response latencies to these three nouns should correlate positively with the values of their relative entropies.

In the experiment that follows, we have considered Serbian nouns belonging to the main masculine and feminine regular ICs. Figure 2 illustrates the similarities and differences between the distributions of forms in these two ICs. In the upper panel, relative frequencies are organized in terms of the proportion of forms within the IC ending in a particular inflectional exponent. The lower panel shows the comparison of distributions in terms of case-number combinations. Two things are worth noticing from this figure: first, the relative distributions in both ICs are very similar when one considers case-number combinations, but they are notably different when one considers the inflectional exponents; second, while in the case-number approach both ICs have the same possible combinations, the number and identity of the inflectional exponents are different across both cases. In our study, we will concentrate on the distribution of different forms, as shown in the upper panel. Not only does this distribution offer us a greater amount of variability across the ICs, but previous research on Serbian indicates that this is the more psychologically relevant distribution (A. Kostić et al., 2003).

In summary, we investigated the role and interrelation of IPs and ICs in recognition of visually presented word stimuli. Participants performed a lexical decision task in which the stimulus words were Serbian nouns. For each noun, the inflectional and relative entropy values were calculated. These were entered as predictors in regression analyses on the word decision latency and error data. It was predicted that relative entropy would be a significant unique predictor of lexical decision performance even when inflectional entropy was included in the regression equations.

\section{Method}

\section{Participants}

One hundred undergraduate students of psychology from the University of Novi Sad took part in the experiment, fulfilling course requirements. They were all native speakers of Serbian and had normal or corrected-to-normal vision. Each participant was exposed to a single experimental treatment.

\section{Materials}

Stimuli were retrieved from the Frequency Dictionary of Contemporary Serbian Language (Đ. Kostić, 1999). Only nouns that are documented to appear in all combinations of case and number were considered for the experiment. We avoided using nouns in the vocative case because of its problematic status (see Đ. Kostić, 1965, for a detailed discussion). 

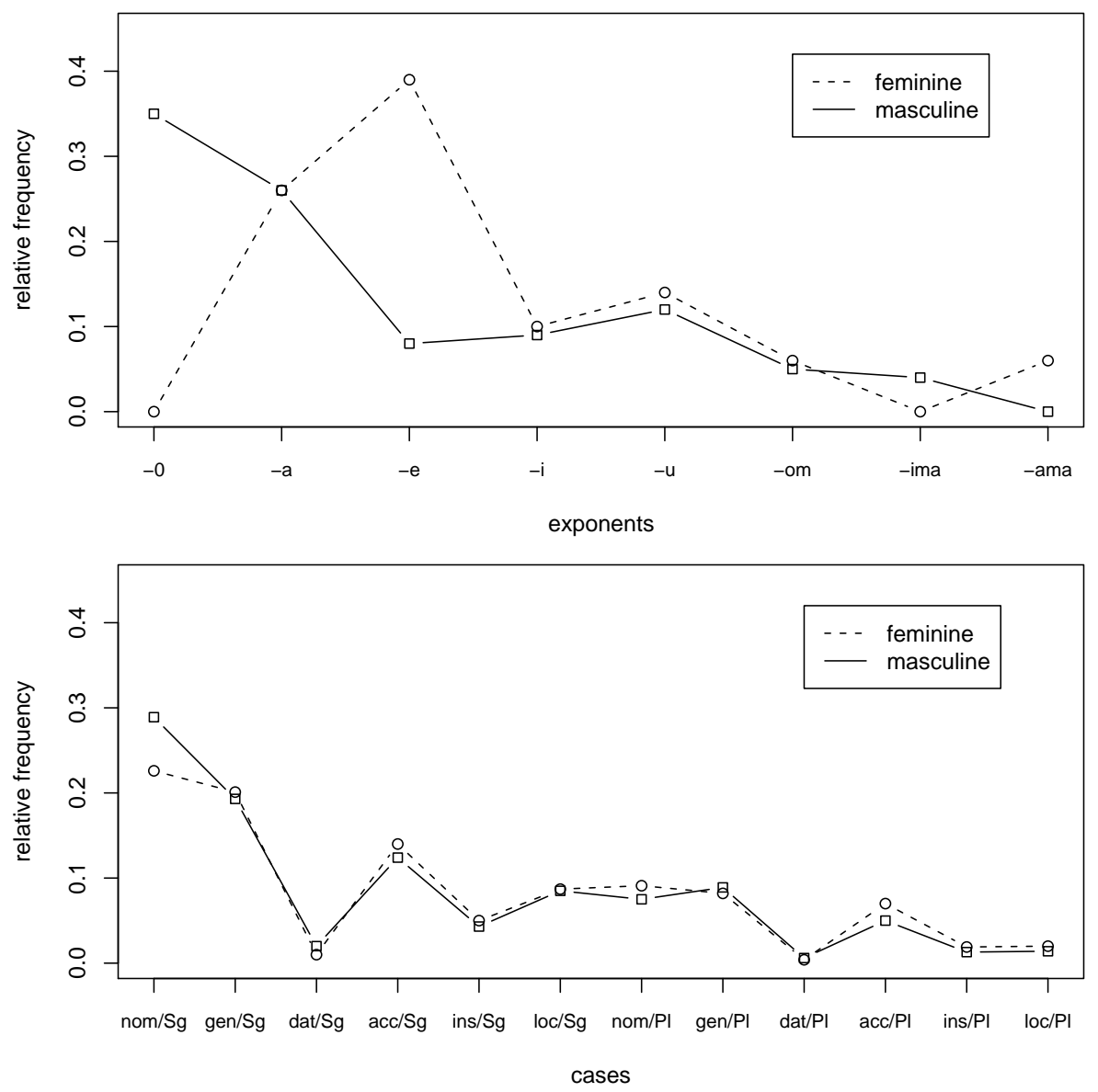

Figure 2. Comparison between the distributions of relative frequencies in the two ICs used in our experiments: masculine nouns (solid lines) and feminine nouns (dashed lines). The lower panel shows the distribution of relative frequencies within each IC organized by case-number combinations. The upper panel shows the same comparison in terms of different forms.

From the nouns that satisfied the above criteria, we selected 70 masculine and 54 feminine nouns to be used in our experiment. Using the method described in the previous section, we computed the inflectional entropy of the word's IP, and the relative entropy between the word's IP's (local) and its IC's (global) frequency distribution. The nouns were selected to cover the whole range of values of the relative entropy measure, which resulted in a larger number of masculine nouns.

As inflectional exponent frequency can influence the recognition of Serbian words in visual lexical decision (cf. A. Kostić et al., 2003), and this variable is likely to be collinear with our relative entropy measure, we held this variable constant by designing four experimental lists (two constant inflectional exponents for the feminine: $-u$ and $-e$, and two for the masculine nouns: - om and $-u$ ), each of which contained nouns with exactly the same inflectional exponent. In order to take into account the possible effects of affixal homonymy (cf. Bertram et al., 2000; A. Kostić et al., 2003), we have chosen four inflectional exponents 
Table 4: Characteristics of the word-stimuli in the experiment. Upper example is masculine noun "prostor" (space), and the lower is the feminine noun "planina" (mountain).

\begin{tabular}{llll}
\hline Gender & $\begin{array}{l}\text { Inflectional } \\
\text { exponent }\end{array}$ & Cases & Example \\
\hline 70 masc. nouns & - om & instr. Sg. & prostor-om \\
& $-\mathrm{u}$ & dat. Sg.; loc. Sg. & prostor- $u$ \\
54 fem. nouns & $-\mathrm{u}$ & acc. Sg. & planin- $u$ \\
& $-\mathrm{e}$ & gen. Sg.; nom. Pl.; & planin- $e$ \\
& & acc. Pl. & \\
\hline
\end{tabular}

with different levels of affixal homonymy. In particular, for each gender we selected one unambiguous inflectional exponent (i.e., it can only mark one combination of case and number, e.g., -om for masculine nouns in instrumental singular, and $-u$ for feminine nouns in accusative singular) and an ambiguous one (i.e., it can mark two or more combinations of case and number, e.g., $-u$ for masculine nouns in dative and locative singular, and $-e$ for feminine nouns in genitive singular and nominative and accusative plural), making sure that the inflectional exponents chosen were not ambiguous with respect to their IPs or ICs (i.e., they were not homonymic with inflected variants of other words). We did not control the average word frequencies, orthographic neighborhoods or bigram frequencies, between the experimental blocks, but rather their effects were left for partialling out in regression analyses, as this is shown to be more adequate for this type of variables (cf. Baayen, Davidson, \& Bates, 2008).

Finally, for each list, an equal number of possible Serbian pseudo-words (following Serbian ortho-phono-tactics) in the same inflected variants were added. By this method we obtained four final experimental lists, two masculine ones (with 140 items each) and two feminine ones (with 108 items each). More details about these lists are given in Table 4, and the full set of items, together with their frequencies, relative entropy values, and other counts, is provided in Appendix A.

Procedure

Each participant was randomly assigned to one of the four experimental lists. The stimuli from the corresponding list were presented in random order (a different randomization for each participant). Visual stimuli were presented in black capital letters (40 points) in $\mathrm{Yu}$ Helvetica font using the Serbian Latin alphabet in the middle of the screen on a white background. The participants performed a visual lexical decision task. They were verbally instructed by the experimenter that they would see a letter string to which they were supposed to react by pressing the 'yes' button when it was a Serbian word or the 'no' button when the letter string was not a Serbian word. The participants were told to react as quickly and accurately as possible.

Each trial started with the visual presentation of a fixation dot for $1500 \mathrm{~ms}$ followed by the target letter string appearing in the middle of the screen. The target letter string remained on the screen until the participant responded or until a maximum of $1500 \mathrm{~ms}$. When the button was pressed, the visual target stimulus disappeared and a new trial was 
triggered immediately.

The experiment was preceded by ten practice trials, which were not considered in further analyses. After the practice set the participant could ask questions. In total, each experimental session lasted less than ten minutes.

Experiments were carried out using the SuperLab Pro 2.0 experimental software (http://www.cedrus.com), running on a PC, with a $266 \mathrm{MHz}$ Pentium II processor, and a standard video-card. The monitor was set to $75 \mathrm{~Hz}$ refresh rate and a resolution of $1024 \mathrm{x}$ 768 pixels. Following the recommendations of the software manufacturer, a Microsoft Serial Mouse was used as input device.

\section{Results}

After preliminary analyses of the data, one subject from the second experimental block (masculine nouns with inflectional exponent $-u$ ) was excluded due to a large number of long response latencies (exceeding 2.5 standard deviations from the grand average). In addition, items that produced more than $20 \%$ of response-errors were also excluded: six items from the first experimental block (masculine nouns with inflectional exponent -om), two from the second block (masculine nouns with inflectional exponent $-u$ ), and two from the third experimental block (feminine nouns with inflectional exponent $-u$ ).

Response latencies, surface and stem frequencies were transformed to logarithmic scale to approximate normality. Surface and stem frequency counts were orthogonalized to avoid problems of collinearity that could arise from their high degree of intercorrelation (for an in-depth discussion of the issue of collinearity in regression analyses see Belsley, 1991). The orthogonalization procedure consisted of fitting a least-squares regression with the log surface frequency as a predictor and $\log$ stem frequency as the dependent variable. The stem frequency count in further analyses was substituted by the residuals of this regression. This technique enables us to account for all the variance that either of the frequency measures can explain, without adding unnecessary collinearity into the model. Note that by doing this we are overlooking the question of which of these frequency counts is a better predictor. However, in our study we are not concerned with this question. These frequency counts are only considered to ensure that any effects of our variable of interest are not confounded with any word frequency effects.

\section{Response latencies}

We performed a multilevel regression analysis on the log-transformed reaction times, using the linear mixed-effect model technique (Baayen et al., 2008; Bates, 2005, 2006). As independent (fixed-effect) predictors, we included: surface frequency (in log scale), stem frequency (the residuals of the log scale orthogonalization), log number of orthographic neighbors (Coltheart, Davelaar, Jonasson, \& Besner, 1977), log bigram frequency (taking the geometric mean of the bigram frequencies for each word, as described in Baayen et al., 2006), binary indicator of affixal homonymy, inflectional entropy (as described by Moscoso del Prado Martín et al., 2004), and the relative entropy between the local and global frequency distributions. In order to obtain comparable magnitudes of effect estimates, all counts were standardized to a $z$-score (after applying the log transformation where applicable). This transformation is innocuous for regression analyses in terms of evaluating the significance 
of effects, but puts all the $\beta$ coefficients in the same scale. In addition, we simultaneously considered the possible random effects of participants, of experimental block, of the gender, and of the item itself. To investigate whether our relative entropy effect was different depending of the gender of the words, we also tested for the possible presence of a mixed effect of the relative entropy by gender. Finally, we investigated possible non-linearities in our effects by including cubic and quadratic terms in the regression analyses. In this way we obtain a very detailed account of the structure of our effects in a single analysis, in a more accurate manner than the traditional techniques (see Baayen et al., 2008, for a more detailed description of this technique and an exhaustive comparison to other analysis techniques).

We observed significant facilitatory main effects of surface frequency $(t(5468)=$ $-7.90, p<.0001)$ and stem frequency residuals $(t(5468)=-3.21, p=.0013)$, and a facilitatory effect of orthographic neighborhood size $(t(5468)=-2.77, p=.0057)$. Importantly, after partialling out the contribution of all other counts, we also observed an inhibitory contribution of the relative entropy $(t(5468)=2.46, p=.0139)$, without any significant contribution of inflectional entropy, affixal homonymy, or the mean bigram frequency (either when considered before or after the relative entropy count). Figure 3 shows that the larger the difference in the frequency distributions between the local and global paradigms, the more time the participants need to recognize the word.

We also tested for a possible mixed effect of gender by relative entropy, but the inclusion of such interaction, if anything, damaged the models. This indicates that the magnitude of the relative entropy effect does not differ significantly between the two genders used in our experiment. Finally, we did not observe any significant non-linear components of the effects (i.e., the quadratic and cubic terms were not significant in the regressions).

As can be appreciated in Figure 3, compared to the magnitude of the frequency effect, the effect of the relative entropy is small but nevertheless reliable. The estimated $\beta$ values for the effect of surface frequency is $\beta=-.042$, with a $95 \%$ confidence interval in the range $[-.0559,-.0308]$. In comparison the $\beta$ values and confidence intervals for the relative entropy effect are $\beta=.010,[.0004, .0191]$. This is about one fourth of the magnitude of the frequency effect, and slightly smaller but not significantly different than the magnitude of the neighborhood density effect $(\beta=-.0135,[-.0253,-.0024])$.

\section{Error counts}

Errors counts were analyzed using a multilevel logistic regression similar to the one described above. In this case, the dependent variable was the logit of the number of correct and incorrect responses per item, the fixed-effect dependent variables were the same as for the RT analysis above (log surface frequency, the residual of the log stem frequency, inflectional entropy, and relative entropy), and the random effects were also the same, excluding the random effect of items (which could not be considered as it gave rise to a singularity in the algorithm). This regression reconfirmed significant main effects of log surface frequency and the stem frequency residuals $(z=-5.15, p<0.0001$ and $z=-2.24, p=0.0253$, respectively). Crucially, as in the case of the RTs, we also observed a significant main effect of the relative entropy $(z=2.64, p=0.0084)$. Neither inflectional entropy, nor bigram frequency, orthographic neighborhood size or the degree of affixal homonymy showed significant effects on the error counts. At most we observed a marginally significant effect of orthographic 

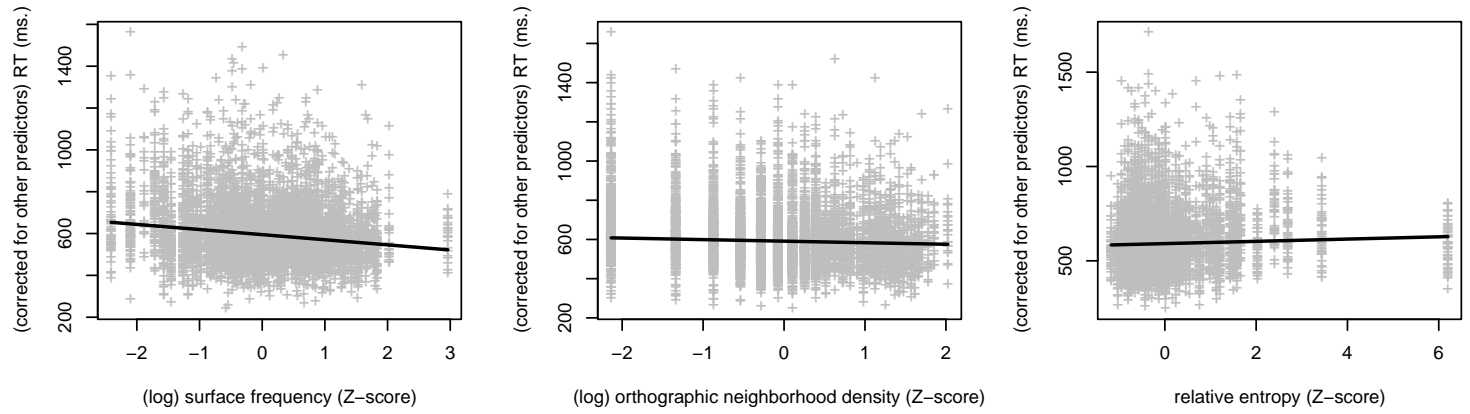

Figure 3. Summary of the effects of $(\log )$ surface frequency, $(\log )$ orthographic neighborhood size, and relative entropy. In order to illustrate the independent contributions of each of the three predictors, the points plotted correspond to the individual reaction times of each subject and each item after considering the effects of all predictors (random \& fixed effects) except for the one being plotted. In addition, to enable direct comparison between the slopes, all predictors have be standardized to Z-scores.

neighborhood size $(z=1.79, p=.0738)$. We did not observe any non-linearities in the effects (i.e., the quadratic and cubic terms were not significant in the regression, $p>.5$ in all cases). Finally, we did not observe any mixed effect (i.e., interaction) between the Gender or Experiment, and the effect of the relative entropy, indicating that the magnitude of the relative entropy effect did not differ across genders or experiments. The direction of the effects reconfirmed that the higher the divergence between the two frequency distributions, the higher the number of errors in the recognition of a word. The relative magnitude of the effects is similar to what we observed in the RT analyses. While the $\beta$ coefficient for the effect of surface frequency is -.39 , the effect of the relative entropy $(\beta=.15)$ is between half and one fourth of that of the surface frequency effect (but nevertheless reliable, as indicated by the $p$ values).

\section{Discussion}

We have investigated the visual recognition of Serbian inflected words with a focus on the two frequency distributions that affect their inflected variants: the IP of the nominal stems, and the broader IC to which the words belong. A tool from basic information theory - the relative entropy - has enabled us to measure the difference between the probability distributions corresponding to the IP and its superseding IC. In our experiment, we observed that the value of this relative entropy is positively correlated with both response latencies and error counts, even when other variables were controlled for, or their effects were partialled out. Our interpretation of these results is relatively straightforward: Both the distribution of inflected variants of a word (its IP), and the distribution of inflected variants within its more general IC influence the recognition of words. When these two distributions differ, lexical recognition is made more difficult in a degree that is log-linearly proportional to the degree of mismatch between the distributions. 
In our study, after considering stem frequency and the relative entropy effect, we did not observe any additional effect of the inflectional entropy measure described by Moscoso del Prado Martín et al. (2004) and Baayen and Moscoso del Prado Martín (2005). ${ }^{4}$ This indicates that it is the divergence between the actual ICs and the IPs that affects lexical recognition more strongly. Furthermore, as the divergence measure that we are introducing is defined in terms of both the IC and the IP, it might be a more adequate measure than the one introduced by Moscoso del Prado Martín and colleagues. One could expect that an even better predictor would be the divergence between the local IP and the grandaverage distribution across all nominal classes. Notice however that such a divergence would show a nearly perfect (i.e., $r \simeq-1.0$ ) correlation with the inflectional entropy count. A simple algebraic expansion of the definition of the relative entropy shows that it is inversely proportional to the entropy of one of the distributions. Thus, if the other distribution is kept constant (as in the distribution across the whole lexicon), both counts are equivalent. Therefore, by not observing an effect of the inflectional entropy, we have also ensured that the distribution of forms in the ICs is more relevant than the distribution of forms across the whole nominal system. In addition, the explicit inclusion of a random effect of Gender in our analyses makes it clear that it is not only that there is a random difference in the processing time for masculine and feminine nouns, but more strongly, that it is the relative entropy that successfully predicts the magnitude of this difference. Notice that the relative entropy effect is significant over and above the random contribution of Gender.

Words can bear simultaneous relationships with a variety of other words through different possible morphological "links". In our case we have considered both the sharing of a stem, and the belonging to a broader IC. If these two differ in probability distributions of inflected forms, conflict can arise, resulting in slower recognition of the words. That is exactly what our results suggest, confirming the influence of both IPs and ICs, as had been suggested in previous studies (Baayen et al., 2006; Baayen \& Moscoso del Prado Martín, 2005; Clahsen et al., 2001; A. Kostić, 1991, 1995; A. Kostić et al., 2003; Moscoso del Prado Martín et al., 2004). Furthermore, our results confirm our interpretation of the results of Baayen, Burani, and Schreuder (1997), Baayen, Dijkstra, and Schreuder (1997), and New et al. (2004): The difference in responses to singular dominant and plural dominant words in their experiments can be a side effect of the conflict between the frequency distribution in the IP of the word and the overall distribution within the general nominal IC. This study has provided a general and detailed way to measure the effects of mismatching paradigms.

In principle, various current theories of the organization of the lexicon offer more or less explicit mechanisms to deal with the simultaneous existence of multiple paradigms. In general, any type of theory that allows for probabilistic links (either through explicit connections or by means of overlapping representations) between the members of an IC could be used to account for our results. The only limiting condition would be to provide a mechanism that allows for the probabilistic properties of all the (possibly nested)

\footnotetext{
${ }^{4}$ Notice that inflectional entropy was entered into the regressions simultaneously with relative entropy (and with all other effects under consideration). Thus, it is not possible to argue that the effect of relative entropy has received any kind of priority over inflectional entropy. Our results suggest that, when relative entropy is considered in the model, inflectional entropy does not have a significant effect on either latencies or errors for this dataset. However, in additional analyses where the relative entropy variable was not entered, the inflectional entropy variable did reach significance, replicating previous findings.
} 
paradigms/classes to which a word belong to influence its recognition, sometimes giving rise to conflict between the different paradigms.

An additional issue that we have left aside in this study, but that needs to be addressed in order to provide a more detailed description of paradigmatic effects, is the role of the syntactic and semantic relationships between the members of the paradigm (cf., A. Kostić, 1991, 1995; A. Kostić et al., 2003). In our experiment we considered this variation by using inflectional exponents with different number of usages, and partialled out possible effects of their degree of ambiguity, but further research is required to investigate how these affect the relations between local IPs and global ICs.

Finer classification of ICs into a larger number of quasi-regular classes, including irregular words of different types is also possible. For instance, verbs in Germanic languages can be classified into a large number of classes ranging from the completely irregular, such as English "to be", to the fully regular ICs that we have concentrated on, and also intermediate regularity classes of many verbs with similar inflectional mechanisms (e.g., "keep" - "kept", "meet" - "met", "leave" - "left", etc.). Baayen and Moscoso del Prado Martín (2005) showed that this kind of (officially irregular) ICs can also influence lexical processing, with the degree of influence being proportional to the (log-)number of words that belong to the IC. We would predict that the effects that we have observed here for the less polemic fully regular cases would likely arise as well for the less regular classes. This prediction remains to be tested explicitly.

We have restricted our investigation to the distribution of inflected variants within ICs, since these are well studied in the psycholinguistic literature (e.g., Baayen, Burani, \& Schreuder, 1997; Baayen, Dijkstra, \& Schreuder, 1997; Burani et al., 1984; Caramazza et al., 1988; Clahsen, 1999; Clahsen et al., 2001; Hyönä et al., 1995; Janssen \& Penke, 2002; A. Kostić, 1991, 1995; A. Kostić et al., 2003; Moscoso del Prado Martín et al., 2004; New et al., 2004; Traficante \& Burani, 2003, etc.). However, an issue that remains unresolved in our data, is whether the effect should be measured on the distributions of inflected forms (e.g., collapsing all forms with the same inflectional exponent irrespective of their case), or considering homonymic forms of different cases separately. In this respect, A. Kostić et al. (2003) provides evidence that the distributions should be computed on the basis of inflected forms, and not on cases. Our main analyses had concentrated on distributions of inflected forms (i.e., inflectional exponents rather than cases). We performed post-hoc analyses on our data using paradigm cells (i.e., cases) instead of forms, but the results were inconclusive: We obtained identical results when we computed the distributions over cases instead of over inflected forms. ${ }^{5}$ Further ad-hoc studies are necessary to better understand this issue.

We have established - for the first time after explicitly controlling other confounding variables - that abstract ICs influence the processing and representation of words in the mental lexicon. The members of an IC do not share stems - although in many cases their stems can show some orthographic, phonological, syntactic or semantic overlap. They also cannot be defined in terms of a single inflectional exponent (or inflectional ending), but rather by the consistent usage of the same inflectional exponents to serve the same

\footnotetext{
${ }^{5}$ In the analysis over paradigm cells, both the masculine and feminine have the same number of cells, and the frequency of each inflected form is broken down into the particular combinations of case and number that can be served by each inflectional ending.
} 
functions. These paradigms are considered by some contemporary linguists as a fundamental building block of language (cf., Blevins, 2006; Hockett, 1957; Matthews, 1972; Stump, 2001). However, from the point of view of psycholinguists, the interplay of IPs and ICs has been mostly overlooked as possible co-determiner of the structure of the mental lexicon. Our study demonstrates that this is indeed the case: the organization of the mental lexicon seems to parallel the descriptions of the lexicon defended in some current linguistic theories such as Word and Paradigm morphology. In general, it seems very difficult for the mental lexicon not to detect and exploit all regularities present in its environment, and inflectional paradigms and classes are no exception to that.

\section{References}

Anderson, S. R. (1992). A-morphous morphology. Cambridge: Cambridge University Press.

Aronoff, M. (1994). Morphology by itself: Stems and inflectional classes. Cambridge, Mass.: The MIT Press.

Baayen, R. H., Burani, C., \& Schreuder, R. (1997). Effects of semantic markedness in the processing of regular nominal singulars and plurals in Italian. In G. E. Booij \& J. v. Marle (Eds.), Yearbook of morphology 1996 (pp. 13-34). Dordrecht: Kluwer Academic Publishers.

Baayen, R. H., Davidson, D. J., \& Bates, D. M. (2008). Mixed-effects modeling with crossed random effects for subjects and items. Journal of Memory and Language, in press.

Baayen, R. H., Dijkstra, T., \& Schreuder, R. (1997). Singulars and plurals in Dutch: Evidence for a parallel dual route model. Journal of Memory and Language, 37, 94-117.

Baayen, R. H., Feldman, L. B., \& Schreuder, R. (2006). Morphological influences on the recognition of monosyllabic monomorphemic words. Journal of Memory and Language, 55, 290-313.

Baayen, R. H., \& Moscoso del Prado Martín, F. (2005). Semantic density and past-tense formation in three Germanic languages. Language, 81(3), 666-698.

Bak, T. H., G., O. D., Xuereb, J. H., Boniface, S., \& Hodges, J. R. (2001). Selective impairment of verb processing associated with pathological changes in Brodmann areas 44 and 45 in the motor neurone diseasedementiaaphasia syndrome. Brain, 124, 103-120.

Bates, D. M. (2005). Fitting linear mixed models in R. R News, 5, 27-30.

Bates, D. M. (2006). Linear mixed model implementation in lme4. Department of Statistics, University of Wisconsin-Madison <http://spider.stat.umn.edu/R/library/lme4/doc/>.

Belsley, D. A. (1991). Conditioning diagnostics: Collinearity and weak data in regression. New York: Wiley.

Bertram, R., Laine, M., Baayen, R. H., Schreuder, R., \& Hyönä, J. (2000). Affixal homonymy triggers full-form storage, even with inflected words, even in a morphologically rich language. Cognition, 74, B13-B25.

Bird, H., Howard, D., \& Franklin, S. (2001). Noun-verb differences? A question of semantics: A response to Shapiro and Caramazza. Brain and Language, 76, 213-222.

Blevins, J. P. (2003). Stems and paradigms. Language, 79(4), 737-767.

Blevins, J. P. (2006). English inflection and derivation. In B. Aarts \& A. M. McMahon (Eds.), Handbook of English linguistics (pp. 507-536). London: Blackwell.

Burani, C., Salmaso, D., \& Caramazza, A. (1984). Morphological structure and lexical access. Visible Language, 18, 342-352.

Caramazza, A., Laudanna, A., \& Romani, C. (1988). Lexical access and inflectional morphology. Cognition, 28, 297-332.

Clahsen, H. (1999). Lexical entries and rules of language: A multidisciplinary study of German inflection. Behavioral and Brain Sciences, 22(6), 991-1060.

Clahsen, H., Hadler, M., Eisenbeiss, S., \& Sonnenstuhl-Henning, I. (2001). Morphological paradigms 
in language processing and language disorders. Transactions of the Philological Society, 99(2), 247-277.

Colé, P., Beauvillain, C., \& Segui, J. (1989). On the representation and processing of prefixed and suffixed derived words: A differential frequency effect. Journal of Memory and Language, 28, $1-13$.

Colombo, L., \& Burani, C. (2002). The influence of age of acquisition, root frequency, and context availability in processing nouns and verbs. Brain and Language, 81, 398-411.

Coltheart, M., Davelaar, E., Jonasson, J. T., \& Besner, D. (1977). Access to the internal lexicon. In S. Dornick (Ed.), Attention and performance (Vol. VI, pp. 535-556). Hillsdale, New Jersey: Erlbaum.

Cover, T. M., \& Thomas, J. A. (1991). Elements of information theory. New York: John Wiley \& Sons.

Damasio, A. R., \& Tranel, D. (1993). Nouns and verbs are retrieved with differently distributed neural systems. Proceedings of the National Academy of Sciences USA, 90, 4957-4960.

De Saussure, F. (1966/1916). Course in general linguistics. New York: McGraw.

Halle, M., \& Marantz, A. (1993). Distributed morphology and the pieces of inflection. In K. Hale \& S. J. Keyser (Eds.), The view from building 20: Essays in linguistics in honor of Sylvain Bromberger (Vol. 24, pp. 111-176). Cambridge, Mass: MIT Press.

Hay, J. B., \& Baayen, R. H. (2005). Shifting paradigms: Gradient structure in morphology. Trends in the Cognitive Sciences, 9, 342-348.

Hockett, C. (1957). Two models of grammatical description. In M. Joos (Ed.), Readings in linguistics $I$ (pp. 386-399). Chicago: University of Chicago Press.

Hyönä, J., Laine, M., \& Niemi, J. (1995). Effects of a word's morphological complexity on readers' eye fixation patterns. In J. M. Findlay, R. W. Kentridge, \& R. Walker (Eds.), Eye movement research: Mechanisms, processes and applications (p. 445-452). Amsterdam: Elsevier.

Janssen, U., \& Penke, M. (2002). How are inflectional affixes organized in the mental lexicon? Evidence from the investigation of agreement errors in agrammatic aphasics. Brain and Language, 81(1-3), 180-191.

Kostić, Đ. (1965). Sintaktičke funkcije padežih oblika u srpskohrvatskom jeziku (Syntactic functions of cases in Serbo-Croatian). Institute for Experimental Phonetics and Speech Pathology, Belgrade, Serbia.

Kostić, Đ. (1999). Frekvencijski rečnik savremenog srpskog jezika (Frequency Dictionary of Contemporary Serbian Language). Institute for Experimental Phonetics and Speech Pathology \& Laboratory of Experimental Psychology, University of Belgrade, Serbia <http://www.serbiancorpus.edu.yu/>.

Kostić, A. (1991). Informational approach to processing inflected morphology: Standard data reconsidered. Psychological Research, 53(1), 62-70.

Kostić, A. (1995). Informational load constraints on processing inflected morphology. In L. B. Feldman (Ed.), Morphological aspects of language processing (pp. 317-344). New Jersey: Lawrence Erlbaum Inc. Publishers.

Kostić, A., \& Katz, L. (1987). Processing differences between nouns, adjectives, and verbs. Psychological Research, 49, 229-236.

Kostić, A., Marković, T., \& Baucal, A. (2003). Inflectional morphology and word meaning: Orthogonal or co-implicative domains? In R. H. Baayen \& R. Schreuder (Eds.), Morphological structure in language processing (pp. 1-44). Berlin: Mouton de Gruyter.

Kuryłowicz, J. (1964). The inflectional categories of Indo-European. Heidelberg: Carl Winter Universitaetsverlag.

Lieber, R. (1992). Deconstructing morphology: Word formation in syntactic theory. Chicago: University of Chicago Press.

Lukatela, G., Gligorijević, B., Kostić, A., \& Turvey, M. T. (1980). Representation of inflected nouns in the internal lexicon. Memory and Cognition, 8, 415-423. 
Matthews, P. H. (1972). Inflectional morphology: A theoretical study based on aspects of latin verb conjugation. Cambridge: Cambridge University Press.

Matthews, P. H. (1991). Morphology. Cambridge: Cambridge University Press.

Moscoso del Prado Martín, F., Kostić, A., \& Baayen, R. H. (2004). Putting the bits together: An information theoretical perspective on morphological processing. Cognition, 94, 1-18.

New, B., Brysbaert, M., Segui, F. L., \& Rastle, K. (2004). The processing of singular and plural nouns in French and English. Journal of Memory and Language, 51, 568-585.

Shannon, C. E. (1948). A mathematical theory of communication. Bell System Technical Journal, 27, 379-423.

Stump, G. T. (2001). Inflectional morphology: a theory of paradigm structure. Cambridge: Cambridge University Press.

Tabak, W., Schreuder, R., \& Baayen, R. H. (2005). Lexical statistics and lexical processing: semantic density, information complexity, sex, and irregularity in dutch. In S. Kepser \& M. Reis (Eds.), Linguistic evidence - empirical, theoretical and computational perspectives. Berlin: Mouton de Gruyter.

Taft, M. (1979). Recognition of affixed words and the word frequency effect. Memory and Cognition, 7, 263-272.

Traficante, D., \& Burani, C. (2003). Visual processing of Italian verbs and adjectives: The role of inflectional family size. In R. H. Baayen \& R. Schreuder (Eds.), Morphological structure in language processing (pp. 45-64). Berlin: Mouton de Gruyter.

Tyler, L. K., Russel, R., Fadili, J., \& Moss, H. E. (2001). The neural representation of nouns and verbs: PET studies. Brain, 124, 1619-1634.

Wunderlich, D., \& Fabri, R. (1995). Minimalist morphology: An approach to inflection. Zeitschrift fr Sprachwissenschaft, 14(2), 236-294.

Zwicky, A. (1985). How to describe inflection. Proceedings of the Berkeley Linguistics Society 11. Berkeley, California. 
Appendix

Experimental Stimuli

Table A1: Feminine noun items with their frequencies (per million) and entropies values

\begin{tabular}{|c|c|c|c|c|c|c|c|}
\hline \multicolumn{2}{|c|}{ Inflectional exponent $-u$} & \multicolumn{2}{|c|}{ Inflectional exponent $-e$} & \multirow[t]{2}{*}{ Stem } & \multirow{2}{*}{$\begin{array}{l}\text { Stem } \\
\text { Freq. }\end{array}$} & \multirow{2}{*}{$\begin{array}{l}\text { Relative } \\
\text { Entropy }\end{array}$} & \multirow{2}{*}{$\begin{array}{c}\text { Inflectional } \\
\text { Entropy }\end{array}$} \\
\hline Word Form & $\begin{array}{l}\text { Surface } \\
\text { Freq. }\end{array}$ & Word Form & $\begin{array}{l}\text { Surface } \\
\text { Freq. }\end{array}$ & & & & \\
\hline KNJIGU & 47.00 & KNJIGE & 125.50 & knjiga & 324.50 & 0.01 & 2.17 \\
\hline REKU & 96.50 & REKE & 243.50 & reka & 732.50 & 0.03 & 2.22 \\
\hline OLUJU & 12.50 & OLUJE & 48.00 & oluja & 139.00 & 0.05 & 2.17 \\
\hline PLANINU & 24.00 & PLANINE & 95.50 & planina & 292.00 & 0.04 & 2.22 \\
\hline BURU & 15.00 & BURE & 58.50 & bura & 171.00 & 0.04 & 2.23 \\
\hline STENU & 15.00 & STENE & 58.50 & stena & 159.00 & 0.06 & 2.35 \\
\hline TRAVU & 76.00 & TRAVE & 204.50 & trava & 735.00 & 0.09 & 2.23 \\
\hline BRIGU & 22.00 & BRIGE & 39.50 & briga & 132.00 & 0.06 & 2.12 \\
\hline KULU & 5.00 & KULE & 33.00 & kula & 78.50 & 0.09 & 2.03 \\
\hline SLIKU & 52.50 & SLIKE & 88.50 & slika & 368.50 & 0.09 & 2.18 \\
\hline ŽELJU & 47.50 & ŽELJE & 120.00 & želja & 397.50 & 0.08 & 2 \\
\hline GRUPU & 19.50 & GRUPE & 94.00 & grupa & 260.50 & 0.06 & 1.98 \\
\hline KUĆU & 122.50 & KUĆE & 258.00 & kuća & 845.00 & 0.06 & 2.29 \\
\hline BRIGADU & 14.00 & BRIGADE & 69.50 & brigada & 187.50 & 0.08 & 1.89 \\
\hline GRANU & 44.50 & GRANE & 259.00 & grana & 628.00 & 0.04 & 2.11 \\
\hline ŠIRINU & 8.50 & ŠIRINE & 31.00 & širina & 77.00 & 0.11 & 2.29 \\
\hline PRIČU & 48.00 & PRIČE & 74.50 & priča & 204.50 & 0.11 & 2.05 \\
\hline ZORU & 130.50 & ZORE & 248.50 & zora & 718.50 & 0.06 & 2.13 \\
\hline FABRIKU & 12.00 & FABRIKE & 74.00 & fabrika & 212.00 & 0.09 & 2.12 \\
\hline SNAGU & 124.00 & SNAGE & 232.50 & snaga & 730.00 & 0.11 & 2.22 \\
\hline RAVNICU & 7.00 & RAVNICE & 22.00 & ravnica & 79.50 & 0.09 & 2.29 \\
\hline MUNJU & 4.50 & MUNJE & 41.00 & munja & 108.00 & 0.12 & 1.97 \\
\hline EKIPU & 13.00 & EKIPE & 36.00 & ekipa & 127.00 & 0.12 & 1.94 \\
\hline ŠKOLU & 53.00 & ŠKOLE & 170.00 & škola & 442.50 & 0.02 & 2.2 \\
\hline NAUKU & 10.50 & NAUKE & 21.00 & nauka & 58.00 & 0.09 & 1.98 \\
\hline DALJINU & 29.50 & DALJINE & 144.50 & daljina & 337.50 & 0.11 & 2.14 \\
\hline RUŽU & 13.50 & RUŽE & 89.00 & ruža & 220.50 & 0.07 & 1.9 \\
\hline STANICU & 15.00 & STANICE & 82.00 & stanica & 222.50 & 0.13 & 2.05 \\
\hline ULICU & 52.50 & ULICE & 212.50 & ulica & 923.50 & 0.18 & 2.39 \\
\hline LIVADU & 11.50 & LIVADE & 59.00 & livada & 209.50 & 0.16 & 2.28 \\
\hline DOLINU & 15.50 & DOLINE & 38.00 & dolina & 143.00 & 0.21 & 2.43 \\
\hline OBALU & 62.50 & OBALE & 124.50 & obala & 463.50 & 0.23 & 2.38 \\
\hline DUŠU & 175.50 & DUŠE & 210.50 & duša & 845.50 & 0.17 & 2.28 \\
\hline STAZU & 30.50 & STAZE & 114.00 & staza & 366.00 & 0.21 & 2.46 \\
\hline TIŠINU & 93.50 & TIŠINE & 128.50 & tišina & 541.00 & 0.13 & 2.21 \\
\hline LEPOTU & 58.00 & LEPOTE & 74.00 & lepota & 254.50 & 0.16 & 2.36 \\
\hline RIBU & 13.50 & RIBE & 73.00 & riba & 191.50 & 0.16 & 1.79 \\
\hline PTICU & 58.50 & PTICE & 333.00 & ptica & 835.50 & 0.15 & 1.73 \\
\hline DUBINU & 27.00 & DUBINE & 61.50 & dubina & 205.00 & 0.09 & 2.39 \\
\hline SILU & 8.00 & SILE & 73.00 & sila & 182.50 & 0.09 & 2.03 \\
\hline POTREBU & 23.50 & POTREBE & 73.50 & potreba & 174.00 & 0.07 & 2.13 \\
\hline VRBU & 5.50 & VRBE & 43.50 & vrba & 88.00 & 0.14 & 1.86 \\
\hline LASTU & 7.50 & LASTE & 64.00 & lasta & 126.50 & 0.1 & 1.8 \\
\hline NJIVU & 13.00 & NJIVE & 101.50 & njiva & 278.00 & 0.07 & 2.11 \\
\hline GLAVU & 184.50 & GLAVE & 187.50 & glava & 683.50 & 0.3 & 2.34 \\
\hline ZENICU & 5.50 & ZENICE & 31.00 & zenica & 85.00 & 0.24 & 2.29 \\
\hline DRŽAVU & 9.00 & DRŽAVE & 106.50 & država & 223.50 & 0.13 & 1.83 \\
\hline ZVEZDU & 33.00 & ZVEZDE & 407.50 & zvezda & 928.00 & 0.15 & 1.83 \\
\hline BRAZDU & 9.00 & BRAZDE & 43.00 & brazda & 82.50 & 0.15 & 2.08 \\
\hline NOTU & 15.00 & NOTE & 7.50 & nota & 61.00 & 0.38 & 2.21 \\
\hline TUGU & 147.00 & TUGE & 171.50 & tuga & 663.00 & 0.21 & 2.16 \\
\hline PUČINU & 18.00 & PUČINE & 23.50 & pučina & 108.50 & 0.49 & 2.39 \\
\hline GODINU & 121.00 & GODINE & 1133.00 & godina & 1910.50 & 0.18 & 1.62 \\
\hline NACIJU & 0.50 & NACIJE & 10.00 & nacija & 36.50 & 0.31 & 1.71 \\
\hline
\end{tabular}


Table A2: Masculine noun items with their frequencies (per million) and entropies values

\begin{tabular}{|c|c|c|c|c|c|c|c|}
\hline \multicolumn{2}{|c|}{ Inflectional exponent $-u$} & \multicolumn{2}{|c|}{ Inflectional exponent $-e$} & \multirow[t]{2}{*}{ Stem } & \multirow{2}{*}{$\begin{array}{l}\text { Stem } \\
\text { Freq. }\end{array}$} & \multirow{2}{*}{$\begin{array}{l}\text { Relative } \\
\text { Entropy }\end{array}$} & \multirow{2}{*}{$\begin{array}{l}\text { Inflectional } \\
\text { Entropy }\end{array}$} \\
\hline Word Form & $\begin{array}{l}\text { Surface } \\
\text { Freq. }\end{array}$ & Word Form & $\begin{array}{l}\text { Surface } \\
\text { Freq. }\end{array}$ & & & & \\
\hline MOSTOM & 11.00 & MOSTU & 21.00 & most & 263.00 & 0.03 & 2.74 \\
\hline VIDIKOM & 16.00 & VIDIKU & 16.50 & vidik & 215.00 & 0.06 & 2.48 \\
\hline POKRETOM & 12.50 & POKRETU & 19.50 & pokret & 182.50 & 0.04 & 2.53 \\
\hline BRODOM & 17.50 & BRODU & 22.00 & brod & 252.50 & 0.06 & 2.78 \\
\hline IZVOROM & 3.00 & IZVORU & 20.00 & izvor & 231.50 & 0.05 & 2.38 \\
\hline ZANOSOM & 11.00 & ZANOSU & 13.00 & zanos & 139.00 & 0.08 & 2.26 \\
\hline ZIDOM & 26.00 & ZIDU & 67.50 & zid & 431.50 & 0.07 & 2.87 \\
\hline SUDOM & 11.00 & SUDU & 13.00 & sud & 102.00 & 0.09 & 2.58 \\
\hline SATOM & 5.00 & SATU & 13.00 & sat & 284.00 & 0.1 & 2.39 \\
\hline APARATOM & 4.50 & APARATU & 7.00 & aparat & 72.00 & 0.08 & 2.22 \\
\hline ZRAKOM & 18.50 & ZRAKU & 37.00 & zrak & 254.50 & 0.08 & 2.62 \\
\hline OTOKOM & 0.50 & OTOKU & 4.00 & otok & 45.50 & 0.08 & 2.41 \\
\hline PREDLOGOM & 7.00 & PREDLOGU & 32.50 & predlog & 282.00 & 0.09 & 2.18 \\
\hline ZAKONOM & 11.00 & ZAKONU & 21.00 & zakon & 215.50 & 0.06 & 2.27 \\
\hline PLODOM & 13.50 & PLODU & 5.50 & plod & 135.00 & 0.11 & 2.68 \\
\hline KROVOM & 34.50 & KROVU & 33.00 & krov & 324.00 & 0.12 & 2.88 \\
\hline OBLIKOM & 2.00 & OBLIKU & 24.00 & oblik & 154.50 & 0.08 & 2.43 \\
\hline OKEANOM & 1.00 & OKEANU & 5.00 & okean & 46.50 & 0.15 & 2.25 \\
\hline VOZOM & 18.00 & VOZU & 14.50 & voz & 196.50 & 0.14 & 2.53 \\
\hline NAPADOM & 2.50 & NAPADU & 4.00 & napad & 104.50 & 0.08 & 2.28 \\
\hline USPEHOM & 15.00 & USPEHU & 12.50 & uspeh & 187.00 & 0.14 & 2.46 \\
\hline DOMOM & 10.50 & DOMU & 84.00 & dom & 418.00 & 0.17 & 2.35 \\
\hline FENJEROM & 3.50 & FENJERU & 1.50 & fenjer & 33.50 & 0.14 & 2.54 \\
\hline RAZGOVOROM & 2.50 & RAZGOVORU & 32.00 & razgovor & 268.50 & 0.11 & 2.5 \\
\hline ZNAKOM & 4.50 & ZNAKU & 12.50 & znak & 133.50 & 0.17 & 2.27 \\
\hline PROBLEMOM & 7.00 & PROBLEMU & 21.00 & problem & 263.50 & 0.1 & 2.51 \\
\hline GLASOM & 81.50 & GLASU & 28.50 & glas & 756.50 & 0.19 & 2.26 \\
\hline VRHOM & 13.00 & VRHU & 47.00 & vrh & 194.00 & 0.17 & 2.82 \\
\hline TRAGOM & 39.00 & TRAGU & 24.00 & trag & 311.50 & 0.17 & 2.53 \\
\hline PROSTOROM & 7.50 & PROSTORU & 33.50 & prostor & 199.00 & 0.1 & 2.42 \\
\hline ZVUKOM & 19.50 & ZVUKU & 15.50 & zvuk & 328.00 & 0.19 & 2.63 \\
\hline PRIMEROM & 4.50 & PRIMERU & 4.00 & primer & 75.00 & 0.13 & 2.1 \\
\hline RADOM & 56.00 & RADU & 151.50 & $\mathrm{rad}$ & 1000.50 & 0.11 & 2.49 \\
\hline GRADOM & 107.50 & GRADU & 172.00 & grad & 1205.00 & 0.2 & 2.41 \\
\hline PROZOROM & 27.00 & PROZORU & 60.50 & prozor & 548.00 & 0.13 & 2.58 \\
\hline KLUBOM & 1.00 & KLUBU & 8.50 & klub & 71.50 & 0.19 & 2.6 \\
\hline BOLOM & 62.00 & $\mathrm{BOLU}$ & 47.50 & bol & 701.50 & 0.23 & 2.2 \\
\hline OBLAKOM & 31.50 & OBLAKU & 34.50 & oblak & 782.50 & 0.17 & 2.52 \\
\hline SAVETOM & 3.00 & SAVETU & 21.50 & savet & 239.00 & 0.11 & 2.07 \\
\hline KORAKOM & 48.50 & KORAKU & 22.50 & korak & 490.50 & 0.15 & 2.53 \\
\hline STIHOM & 12.00 & STIHU & 10.00 & stih & 145.50 & 0.23 & 2.86 \\
\hline ZAVODOM & 1.00 & ZAVODU & 11.50 & zavod & 77.50 & 0.12 & 2.21 \\
\hline VRTOM & 9.50 & VRTU & 36.50 & vrt & 145.00 & 0.21 & 2.45 \\
\hline VINOGRADOM & 2.00 & VINOGRADU & 9.50 & vinograd & 104.00 & 0.17 & 2.52 \\
\hline NARODOM & 16.50 & NARODU & 61.00 & narod & 810.00 & 0.11 & 2.15 \\
\hline UGOVOROM & 12.00 & UGOVORU & 9.50 & ugovor & 181.50 & 0.26 & 1.93 \\
\hline ODBOROM & 4.00 & ODBORU & 29.00 & odbor & 526.00 & 0.17 & 2 \\
\hline VEKOM & 6.00 & VEKU & 3.00 & vek & 264.00 & 0.21 & 2.66 \\
\hline FONDOM & 0.50 & FONDU & 3.00 & fond & 90.00 & 0.26 & 2.3 \\
\hline PONOROM & 9.00 & PONORU & 8.50 & ponor & 108.00 & 0.19 & 2.48 \\
\hline VIHOROM & 2.50 & VIHORU & 9.50 & vihor & 92.50 & 0.15 & 2.23 \\
\hline LOGOROM & 4.50 & LOGORU & 17.50 & logor & 79.50 & 0.2 & 2.48 \\
\hline KRUGOM & 17.00 & KRUGU & 55.50 & krug & 316.50 & 0.16 & 2.71 \\
\hline ZAHTEVOM & 2.50 & ZAHTEVU & 5.50 & zahtev & 112.50 & 0.15 & 2.44 \\
\hline CILJEM & 12.50 & CILJU & 71.00 & cilj & 214.00 & 0.33 & 2.38 \\
\hline GREBENOM & 0.50 & GREBENU & 5.50 & greben & 28.50 & 0.28 & 2.45 \\
\hline POGLEDOM & 55.50 & POGLEDU & 131.00 & pogled & 519.50 & 0.32 & 2.19 \\
\hline LOKALOM & 2.00 & LOKALU & 3.00 & lokal & 55.50 & 0.36 & 1.98 \\
\hline PAŠNJAKOM & 2.00 & PAŠNJAKU & 2.50 & pašnjak & 31.00 & 0.29 & 2.6 \\
\hline DRUMOM & 50.50 & DRUMU & 44.00 & drum & 270.00 & 0.37 & 2.88 \\
\hline ŽIVOTOM & 71.00 & ŽIVOTU & 174.00 & život & 1711.50 & 0.27 & 1.7 \\
\hline NAPOROM & 4.50 & NAPORU & 4.00 & napor & 105.50 & 0.36 & 2.56 \\
\hline VRATOM & 3.00 & VRATU & 26.50 & vrat & 125.50 & 0.24 & 2.17 \\
\hline OSMEHOM & 48.50 & OSMEHU & 9.50 & osmeh & 360.00 & 0.44 & 1.83 \\
\hline SAVEZOM & 2.50 & SAVEZU & 21.50 & savez & 258.50 & 0.38 & 1.65 \\
\hline INTERESOM & 1.00 & INTERESU & 19.50 & interes & 112.00 & 0.53 & 2.56 \\
\hline RUBOM & 15.00 & RUBU & 56.50 & rub & 134.00 & 0.63 & 2.44 \\
\hline ODNOSOM & 0.50 & ODNOSU & 37.00 & odnos & 243.50 & 0.33 & 2.48 \\
\hline ORGANOM & 0.50 & ORGANU & 1.00 & organ & 68.00 & 0.39 & 2.24 \\
\hline PRSTOM & 22.00 & PRSTU & 6.00 & prst & 336.00 & 0.99 & 2.62 \\
\hline
\end{tabular}


Table A3: Serbian pseudo-words in four experimental lists

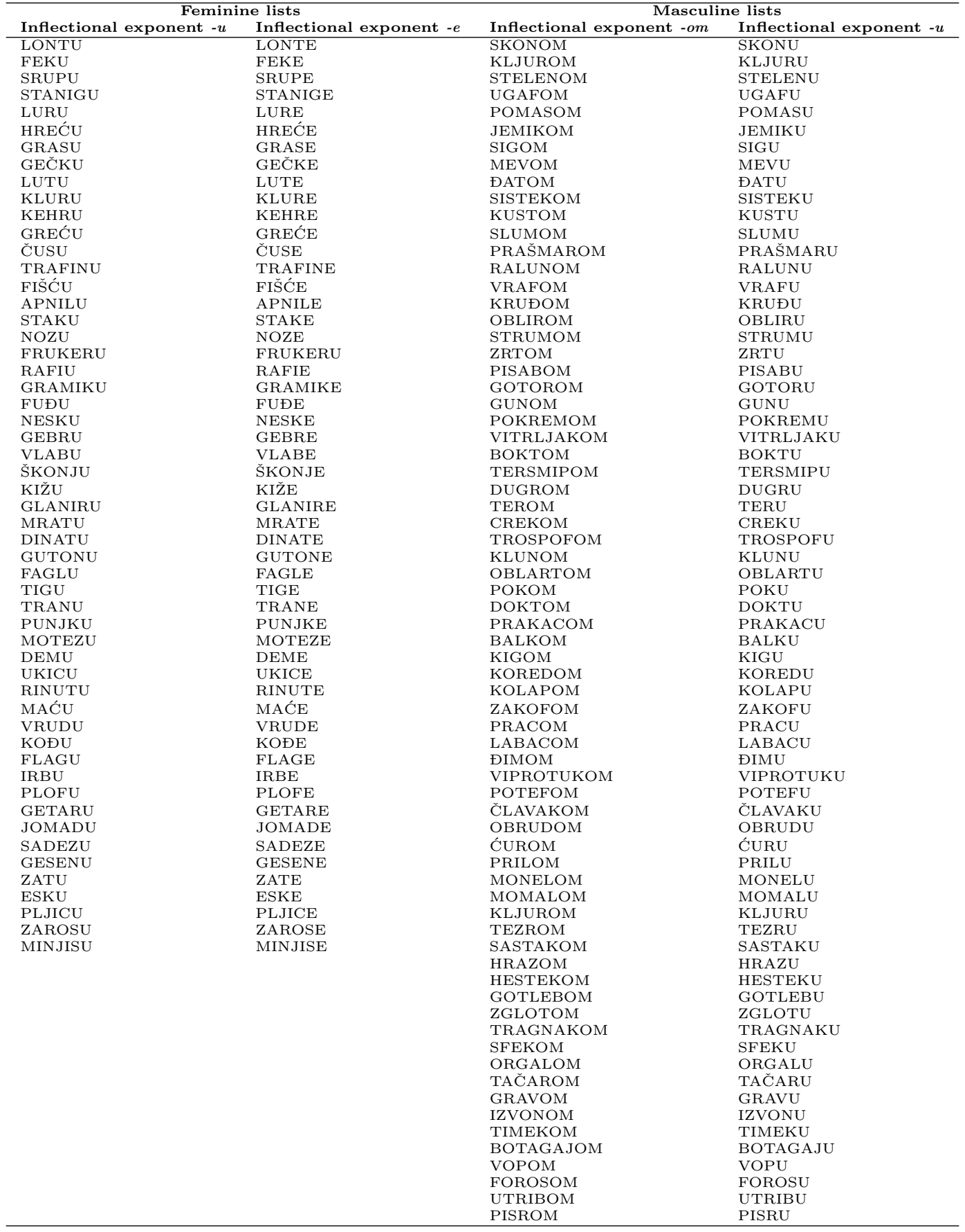

